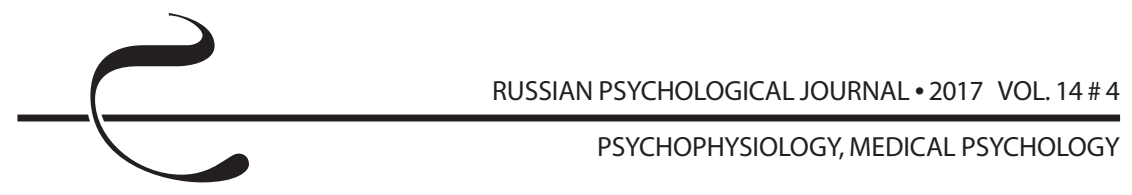

УДК 612.821:618.173:612.67

DOI: $10.21702 / \mathrm{rpj} .2017 .4 .6$

\title{
Особенности психологического статуса женщин перименопаузального возраста с признаками климактерического синдрома
}

\author{
Дмитрий А. Лебедев ${ }^{1 *}$, Александр В. Черноситов ${ }^{1,2}$, Татьяна Л. Боташева ${ }^{2}$ \\ Южный федеральный университет, г. Ростов-на-Дону, Российская Федерация \\ ФГБОУ ВО РостГМУ Минздрава России, г. Ростов-на-Дону, Российская Федерация \\ ${ }^{*}$ E-mail: hunterld@ya.ru
}

\begin{abstract}
Аннотация
Введение. ЗАоровье женщины - важная цель современных медицинских, психо^огических, социальных исследований. Актуальность Аанной проблемы вызвана, с оАной стороны, Увеличением среАней проАолжительности жизни, а с Аругой, совокупностью неблагоприятных внешних и внутренних негативных фракторов, приводящих к ухудшению психоэмоционального статуса, и сопровожАающихся признаками психофизиологической Аезалаптации. В особую зону риска попаАают женщины перименопаузального возраста с так называемым кАимактерическим синдромом. Новизна предпринятого исслеАования заключается в обнаружении психологических особенностей перименопаузы, осложненной климактерическим синАромом.
\end{abstract}

Метолы. У 143 женщин менопаузального возраста (45-55 ^ет) с помощью комплекса взаимно Аополняющих методик (опросник «Ваше самочувствие» (О. С. Копина, ^. Ридер), методика «Оценка нервно-психического напряжения» (Т. А. Немчин), экспресс-Аиагностика ск^онности к немотивированной тревожности (В. В. Бойко), методика Аиагностики самооценки уровня тревожности (Ч. А. Спилберг, Ю. А. Ханин), инАивиАУально-типологический опросник (ИТО) (^. Н. Собчик), метоАика САН (Аиагностика самочувствия, активности и настроения; В. А. Аоскин и соавторы)) выявлены психологические особенности женщин с клиническими признаками климактерического синдрома, по сравнению с женщинами менопаузального возраста без кАимактерического синАрома.

Результаты. По результатам проводимого исследования, авторам удалось выявить неАостаточно изученные особенности ^ичностных свойств менопаузальных женщин с наличием и отсутствием кАимактерического синАрома. Бы^а отмечена Аостоверная связь межАу показателем мичностной тревожности и наличием кАимактерического синдрома у женщин менопаузального периода.

Обсуждение результатов. Результаты, полученные авторами, способны расширить преАставления о психологии женского климактерия, т. к. могут помочь в улучшении способов Аиагностики и психокоррекции кАимактерического синАрома. В Аальнейшем полученные Аанные будут использованы А^я продолжения исслеАования 
в п^ане обнаружения биоэлектрических и биоэнергетических процессов, которые яв^яются ффунаментом ^ичностных особенностей, обнаруженных при климактерическом синароме.

\title{
КАючевые слова
}

перименопауза, репродуктивный возраст, климактерический синАром, объективные проявления климакса, субъективные проявления климакса, психоэмоциональный статус, ^ичностная тревожность, ситуативная тревожность, ^атеральный повеленческий профри^ь, декстральная ^атеризация

\section{Основные положения}

- у женщин с климактерическим синАромом, в отличие от женщин без признаков климактерического синарома, выявлено Аоминирование ^ичностной тревожности; - мичностная тревожность может быть рассмотрена не только как важнейший маркер, но и как прогностический признак появления кАимактерического синАрома в периол предменопаузы;

- у женщин без климактерического синарома общий показатель «сензитивность» имеет Аостоверную связь с «тревожностью» и «активностью» (САН), что существенно отличает их от женщин с наличием климактерического синдрома.

\section{Для цитирования}

Лебедев Д. А., Черноситов А. В., Боташева Т. Л. Особенности психологического статуса женщин перименопаузального возраста с признаками климактерического синдрома // Российский психологический журнал. - 2017. - Т. 14, № 4. - С. 121-137.

Материалы статьи получены 24.05.2017

\section{Psychological Status of Perimenopausal Women with Climacteric Syndrome}

\author{
Dmitrii A. Lebedev ${ }^{1 *}$, Aleksandr V. Chernositov ${ }^{1,2}$, Tat'yana L. Botasheva ${ }^{2}$ \\ 1 Southern Federal University, Rostov-on-Don, Russian Federation \\ ${ }^{2}$ Rostov State Medical University, Rostov-on-Don, Russian Federation \\ *Correspondence author. E-mail: hunterld@ya.ru
}

\begin{abstract}
Introduction. Women's health is an important goal of modern medical, psychological, and social research. Unfavorable external and internal negative factors, which worsen
\end{abstract}




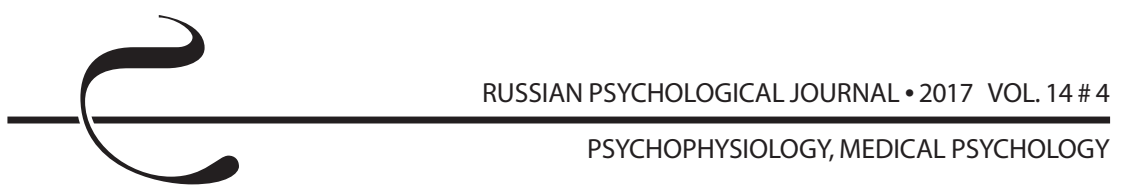

psychoemotional status and lead to psychophysiological disadaptation, and also the increase in life expectancy determine the importance of the issue. Perimenopausal women with the so-called climacteric syndrome are at special risk. The novelty of the research lies in studying psychological characteristics of perimenopause complicated with climacteric syndrome.

Methods. The study used the following techniques: (a) "Your Health", a questionnaire developed by O. S. Kopina and L. Reader; (b) "Assessing Neuropsychic Stress", a technique by T. A. Nemchin; (c) the Rapid Diagnosis of Predisposition to Unwarranted Anxiety by V. V. Boyko; (d) the State-Trait Anxiety Inventory (STAI) by Ch. D. Spielberg and Yu. L. Khanin; (e) the Individual Typological Questionnaire (ITQ) by L. N. Sobchik; (f) and a technique for diagnosing health, activity, and mood - HAM test - developed by $\vee$. A. Doskin and co-authors. The participants comprised 143 menopausal women aged $45-55$ years.

Results. The study revealed the insufficiently explored personality characteristics in menopausal women with and without climacteric syndrome. Personal anxiety and climacteric syndrome had a statistically significant relationship in perimenopausal women. Discussion. The findings contribute to a better understanding of the psychology of menopause and help in improving methods for diagnosis and psychocorrection of climacteric syndrome. Further research will concentrate on the bioelectric and bioenergetic processes forming the basis for personality characteristics in women with climacteric syndrome.

\section{Keywords}

perimenopause, reproductive age, climacteric syndrome, objective manifestations of menopause, subjective manifestations of menopause, psychoemotional status, personal anxiety, situational anxiety, lateral behavioral profile, dextral laterization

\section{Highlights}

- Compared to women without symptoms of menopause, women with climacteric syndrome have a prominent personal anxiety.

- Personal anxiety may be the most important marker and also a prognostic factor for climacteric syndrome in premenopause.

- Unlike the women with climacteric syndrome, the overall index of sensitivity has a statistically significant relationship with anxiety and activity in women without climacteric syndrome (by the HAM test).

\section{For citation}

Lebedev D. A., Chernositov A. V., Botasheva T. L. Psychological Status of Perimenopausal Women with Climacteric Syndrome. Rossiiskii psikhologicheskii zhurnal - Russian Psychological Journal, 2017, V. 14, no. 4, pp. 121-137 (in Russian).

Original manuscript received 24.05.2017 


\section{Введение}

Сохранение здоровья женщин на различных этапах онтогенеза, минимизация заболеваемости, снижение темпов старения, сохранение профессионального долголетия занимают важное место в современных медико-биологических исследованиях $[1,2,3,4]$.

Психологическое развитие тесно связано с физиологическим созреванием организма. Из-за стремительных изменений среды обитания, темпов жизни женский организм все больше становится мишенью влияния внешних стрессовых факторов, приводящих к изменению психоэмоционального статуса, что сопровождается у многих признаками психофизиологической дезадаптации $[5,6,7]$.

Особо уязвимыми к таким факторам женщины становятся в период менопаузы на фоне постепенного угасания репродуктивных функций, общего снижения уровня здоровья и исчезновения сексуальной привлекательности, что связано с изменениями в эндокринной системе $[8,9,10,11]$.

Перименопауза характеризуется инволюционными процессами в яичниках с обязательным ослаблением их гормонопродукции. Показано, что эстрогендефицитное состояние у 60-80\% женщин сопровождается существенными нервными, вегетативными, обменными и психоэмоциональными нарушениями $[12,13,14,15]$.

Наибольшее акцентирование этих нарушений имеет место при так называемом климактерическом синдроме (КС), отмечаемом у 65-70\% женщин $[16,17,18,19]$.

Менопауза является одним из самых драматичных периодов в жизни женщины, сопровождающимся психопатологическими нарушениями. Закономерной компонентой менопаузальных психических отклонений является преобладающее доминирование негативных эмоций - тревоги, страха, гнева, тоски [20, 21, 22].

Клинические проявления тревожно-депрессивных расстройств при КС указывают на атипичную депрессию (по классификации DSM-IV R) [23].

Несмотря на значительное количество работ в этом плане [24, 25, 26, 27, $28,29]$, четких отличий психологического статуса при неосложненной, так называемой физиологической, менопаузе и менопаузе с явными признаками КС в доступной литературе найти не удалось.

Цель исследования: сравнительный анализ индивидуально-личностных особенностей у женщин менопаузального возраста с отсутствием и наличием КС.

\section{Методы}

Исследование было проведено на 143 женщинах - сотрудницах Ростовского НИИ акушерства и педиатрии, которые давали информированное 


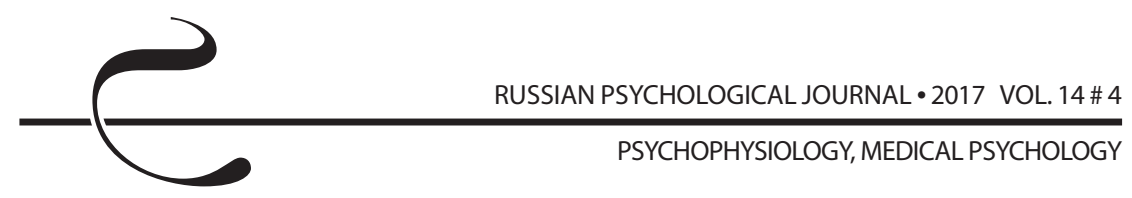

согласие на проведение психологического обследования с использованием методик [30]:

1. Опросник «Ваше самочувствие» (О.С. Копина, Л. Ридер).

2. Методика «Оценка нервно-психического напряжения» (Т. А. Немчин).

3. Экспресс-диагностика склонности к немотивированной тревожности (В.В. Бойко).

4. Методика диагностики самооценки уровня тревожности (Ч.Д. Спилберг, Ю.Л. Ханин).

5. Индивидуально-типологический опросник (ИТО) (Л.Н. Собчик).

6. Методика САН (методика диагностики самочувствия, активности и настроения) (В.А. Доскин и соавторы).

Были соблюдены строгие условия времени проведения, последовательности и кратности исследований.

Включение женщин в группы менопаузальных с отсутствием признаков климактерического синдрома (МПбКС) и менопаузальных с признаками климактерического синдрома (МПсКС) проводили на основании заключений акушеров-гинекологов РНИИАП. Из выборки исключали женщин с хроническими неврологическими, гинекологическими и соматическими заболеваниями. Для унификации данных в исследовании принимали участие женщины только с декстральным латеральным поведенческим профилем, определяемым по методике M. Annett.

Группу сравнения составляли 33 женщины репродуктивного возраста (30-45 лет) с нормальным менструальным циклом, у которых исследование проводили в 1-й фазе менструального цикла.

Все обследованные женщины регулярно проходили плановую диспансеризацию, имеют высшее и среднее специальное медицинское образование со стажем работы от 10 лет, состоят в браке, не имеют вредных привычек. Таким образом, они составляли единообразную социальную группу, что способствовало чистоте и достоверности результатов.

Полученные результаты были подвержены статистической обработке данных с целью определения значимости межгрупповых различий (ранговый критерий Крускала - Уоллиса) и средних значений по группам (t-критерий Стьюдента) в программе SPSS22.

\section{Результаты}

При использовании опросника «Ваше самочувствие» (О.С. Копина, Л. Ридер) у женщин МПбКС отмечен наивысший уровень самооценки здоровья, который даже превышает таковой для женщин репродуктивного возраста.

По шкале «психосоциальный стресс» женщины МПсКС опережают женщин МПбКС и находятся в зоне риска нуждающихся в психологической помощи. 
По остальным шкалам данной методики - «удовлетворенность жизнью» и «удовлетворенность потребностями» - существенного различия между женщинами МПбКС и МПсКС, а также в сравнении этих двух групп с женщинами репродуктивного возраста, отмечено не было (рисунок 1).

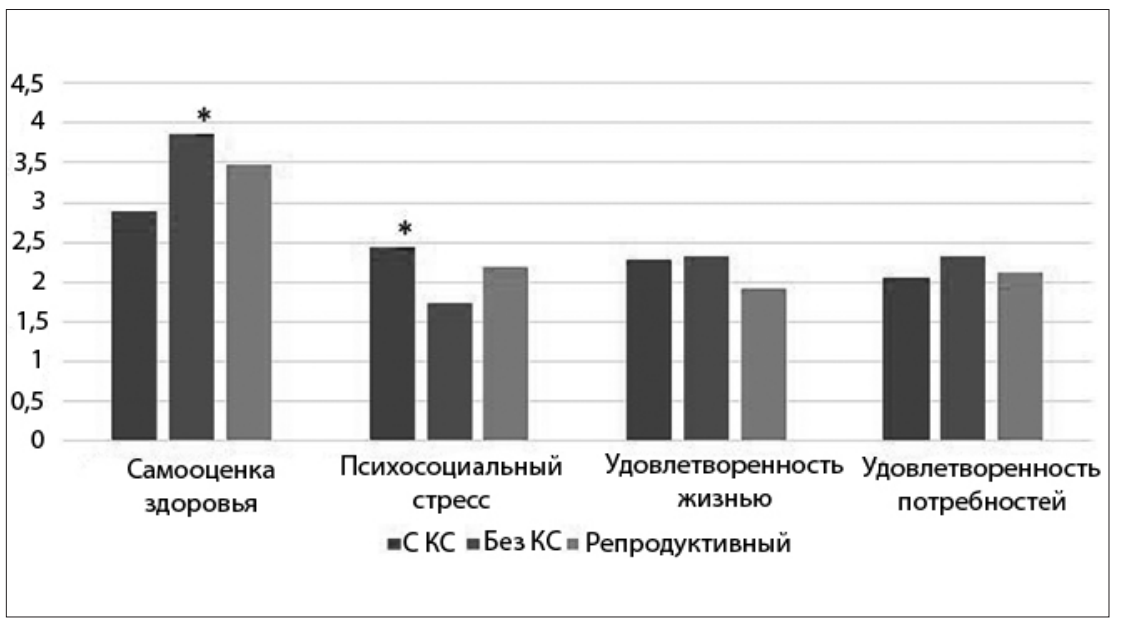

Рисунок 1. Результаты опросника «Ваше самочувствие» (в условных единицах, среднее откАонение)

* - статистическая значимость при p =0,02 между женщинами МПбКС и МПсКС.

Figure 1. Your Health questionnaire (arbitrary units, mean deviation)

* at the 0.02 level of significance (between menopausal women with and without climacteric syndrome).

Значительно более выраженными были отличия между женщинами с менопаузой, осложненной KC, менопаузальными женщинами без признаков KC и женщинами репродуктивного возраста, которые были выявлены при оценке показателей по методике «Оценка нервно-психического напряжения» (рисунок 2).

Высокий уровень нервно-психического напряжения у женщин с КС сочетался с показаниями экспресс-диагностики склонности к немотивированной тревожности (рисунок 3).

Факт наличия повышенной тревожности у женщин МПСК можно было также наблюдать и по результатам диагностики самооценки уровня тревожности (рисунок 4). В свою очередь, женщинам с МПбКС и женщинам в репродуктивном возрасте присуща умеренная тревожность, что соответствует общепринятым нормам. 


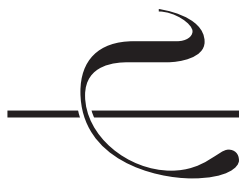

RUSSIAN PSYCHOLOGICAL JOURNAL・ 2017 VOL. 14 \# 4

PSYCHOPHYSIOLOGY, MEDICAL PSYCHOLOGY

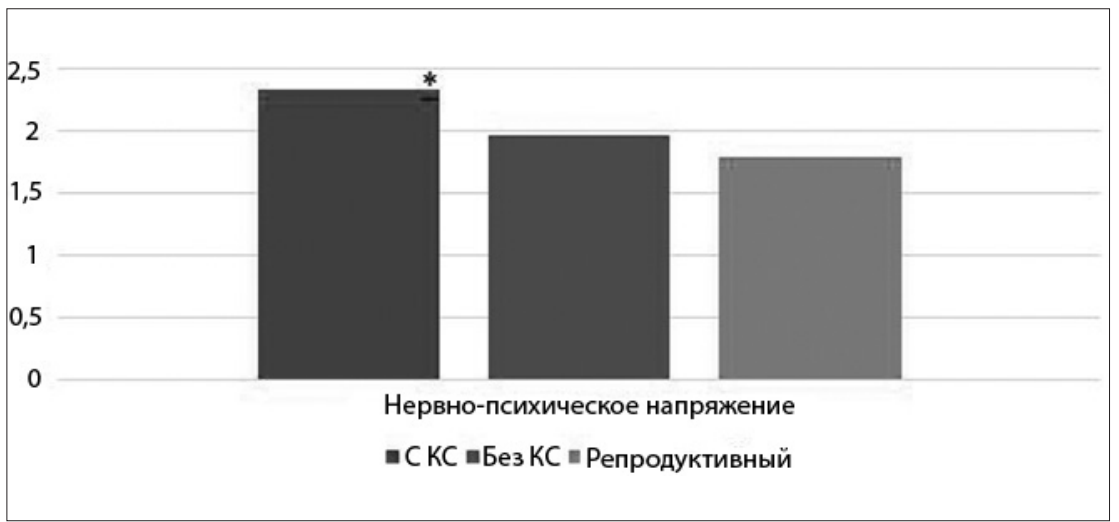

Рисунок 2. Результаты по метолике «Оценка нервно-психического напряжения» (в условных еАиницах, среднее отклонение)

* - статистическая значимость при $p=0,02$ между женщинами МПбКС и МПсКС.

Figure 2. Assessing Neuropsychic Stress technique (arbitrary units, mean deviation)

* at the 0.02 level of significance (between menopausal women with and without climacteric syndrome).

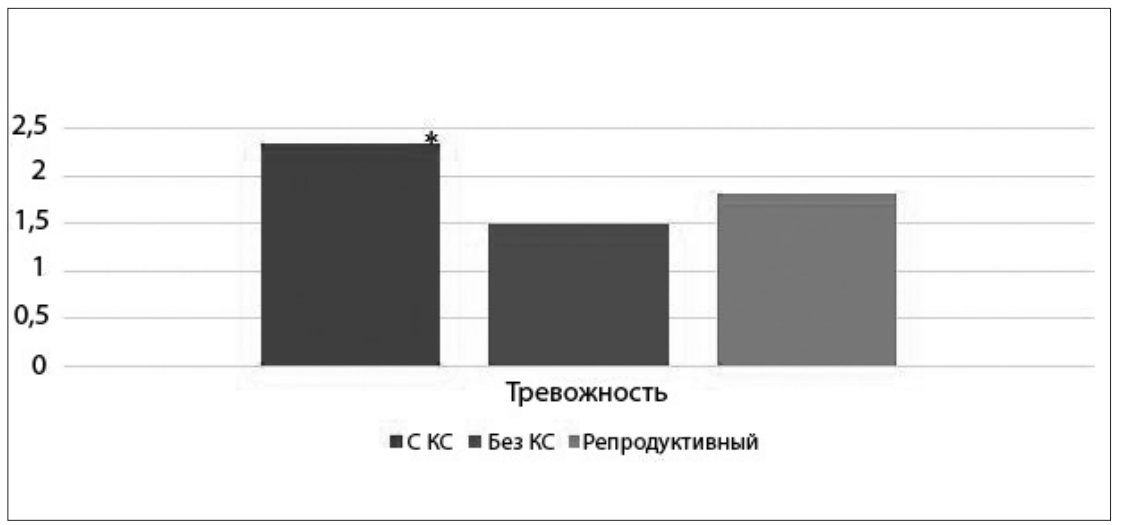

Рисунок 3. Результаты экспресс-Аиагностики ск^онности к немотивированной тревожности (В.В. Бойко) (в условных еАиницах, среднее отклонение)

* - статистическая значимость при $p=0,02$ между женщинами МПбКС и МПсКС.

Figure 3. Rapid Diagnosis of Predisposition to Unwarranted Anxiety (arbitrary units, mean deviation)

* at the 0.02 level of significance (between menopausal women with and without climacteric syndrome). 


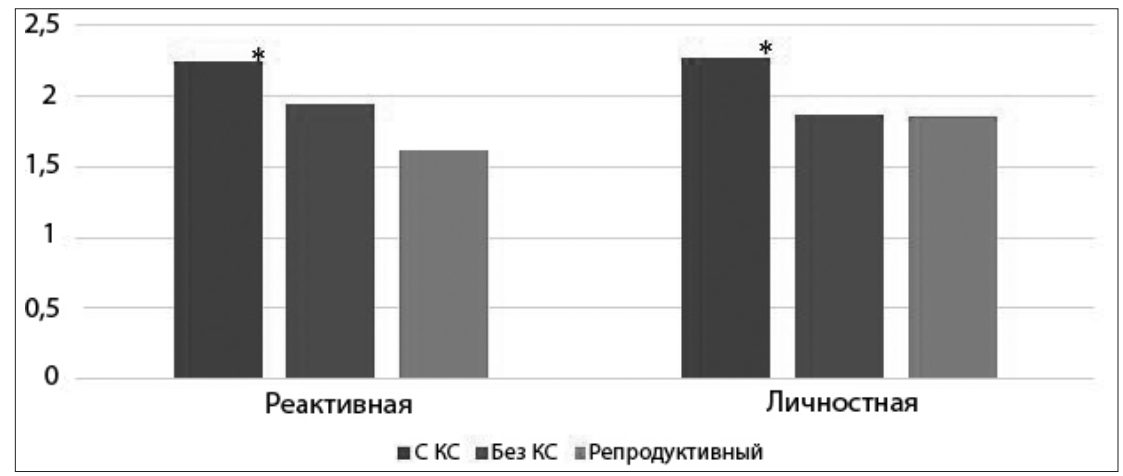

Рисунок 4. Результаты Аиагностики самооценки уровня тревожности (Ч.А. Спи^берга, Ю.А. Ханина) (в условных единицах, среднее отклонение) * - статистическая значимость при р =0,02 между женщинами МПбКС и МПсКС.

Figure 4. State-Trait Anxiety Inventory (arbitrary units, mean deviation)

* at the 0.02 level of significance (between menopausal women with and without climacteric syndrome).

По результатам методики САН (самочувствие, активность и настроение) можно отметить снижение активности у женщин МПбКС и МПсКС, по сравнению с женщинами репродуктивного возраста, и плавное ухудшение самочувствия с преобладанием плохого настроения (рисунок 5).

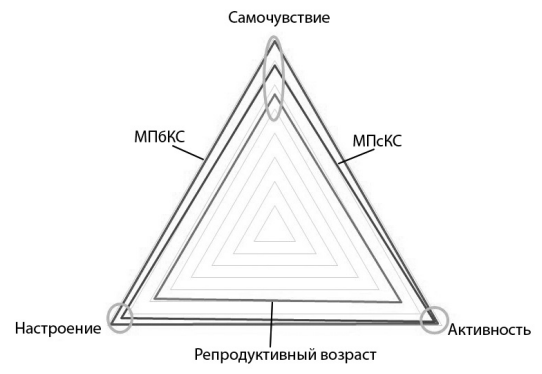

Рисунок 5. Результаты обслелования по метолике САН (самочувствие, активность и настроение) (в условных еАиницах, среАнее отклонение) * - статистическая значимость при р =0,02 между женщинами МПбКС и МПсКС.

Figure 5. HAM test (arbitrary units, mean deviation)

* at the 0.02 level of significance (between menopausal women with and without climacteric syndrome). 
Так, для женщин группы МПсКС был характерен высокий уровень показателей «тревожности» в сочетании с «сензитивностью», что демонстрировало повышенную озабоченность собственными трудностями, проблемами родных и близких, а также повышенную впечатлительность по отношению к окружающим событиям и пессимистический взгляд на будущее.

У менопаузальных женщин без признаков КС, в отличие от женщин с КС, были акцентуированы шкалы «интроверсия» и «сензитивность», что свидетельствует о стремлении у таких женщин к обособленной деятельности и невысокой общительности.

Согласно методике ИТО, женщины репродуктивного возраста в большинстве своем характеризовались экстравертированностью, повышенной активностью, обильными социальными контактами, нескрываемыми желаниями в достижении производственных успехов (рисунок 6).

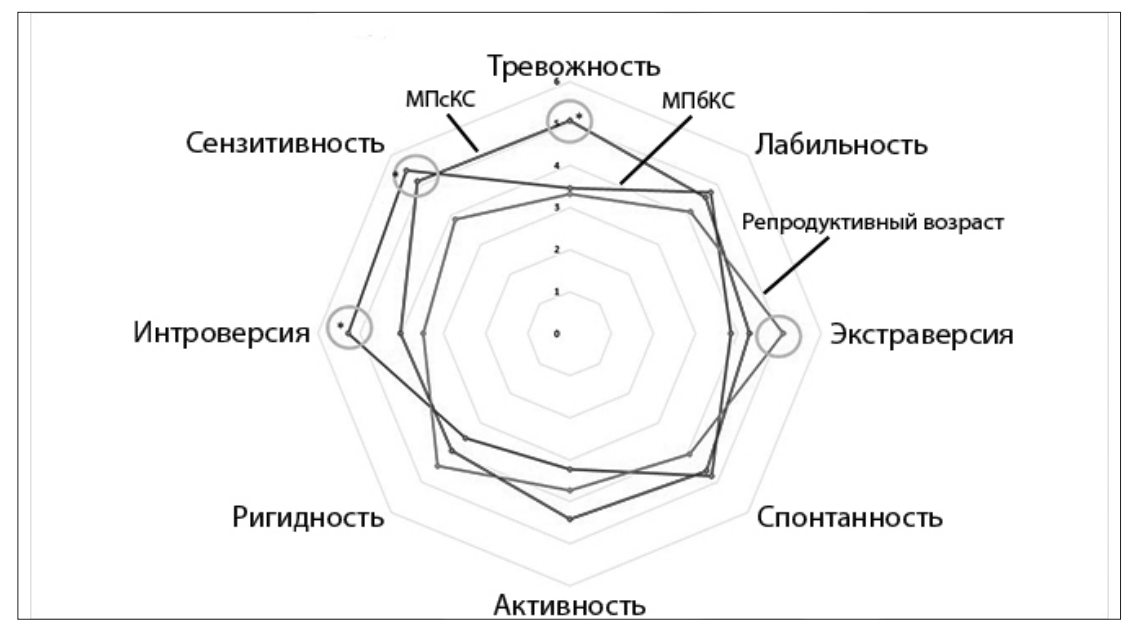

Рисунок 6. Результаты инАивиАуально-типологического опросника (ИТО)

в условных бал^ах

* - статистическая значимость при p =0,02 между женщинами МПбКС и МПсКС.

Figure 6. Individual Typological Questionnaire (arbitrary units)

* at the 0.02 level of significance (between menopausal women with and without climacteric syndrome).

Для понимания взаимосвязи психологических факторов между собой и возможности интеграции результатов в психосоциальный вектор развития женщин нами был проведен корреляционный анализ шкал всех методик для женщин МПсКС и женщин МПбКС (рисунки 7 и 8). 


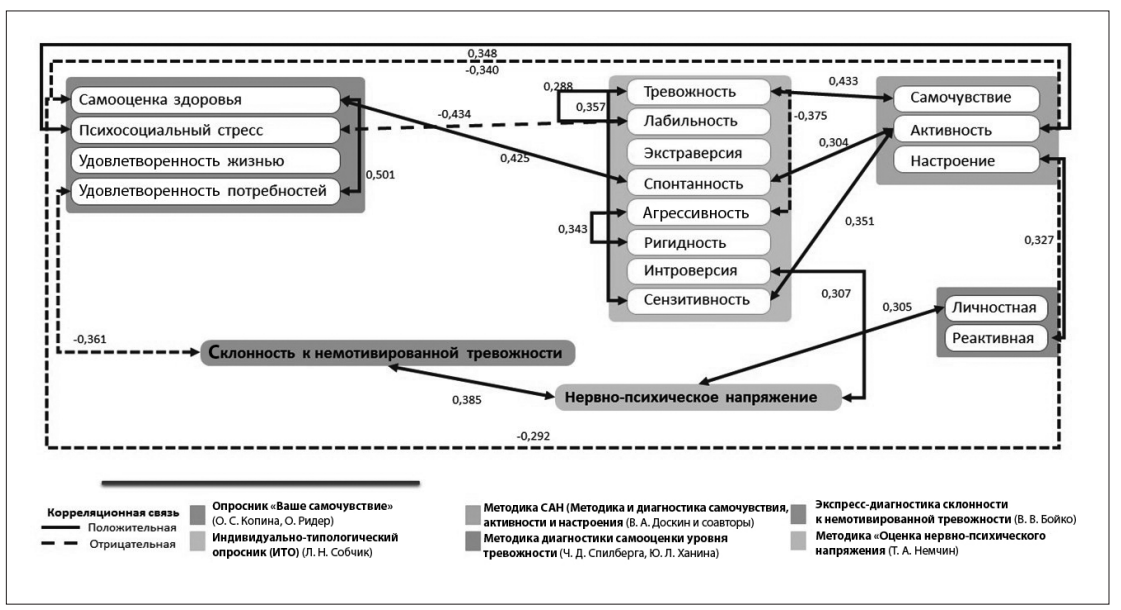

Рисунок 7. Корреляционная зависимость результатов всех использованных метолик Аля женщин МПсКС

Figure 7. Correlation among the variables by all the techniques for menopausal women with climacteric syndrome

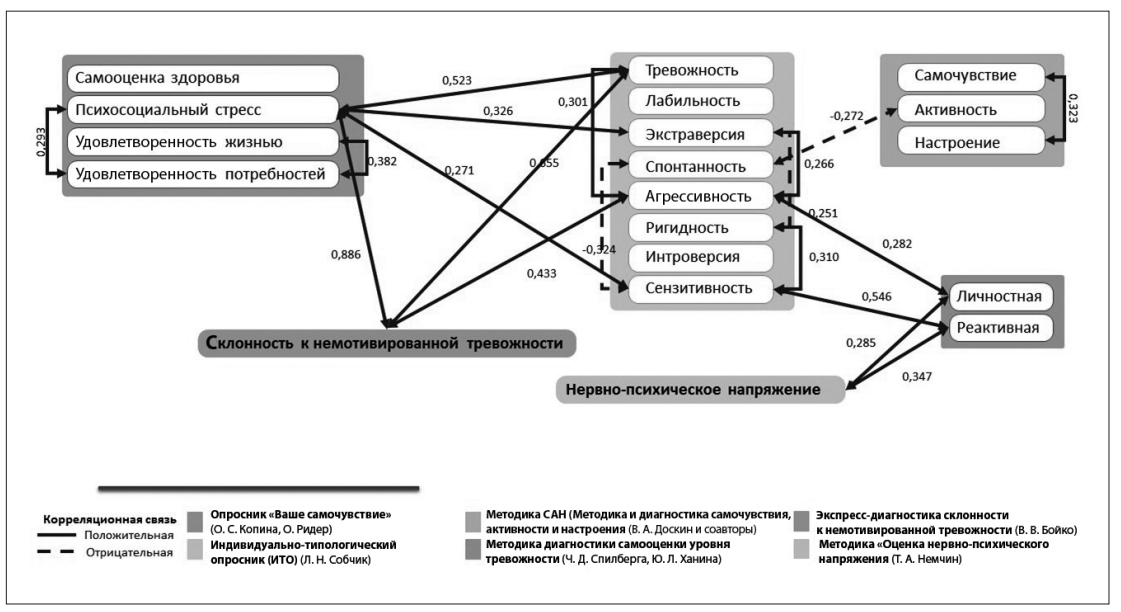

Рисунок 8. Корреляционная зависимость результатов всех использованных метолик Аля женщин МПбКС

Figure 8. Correlation among the variables by all the techniques for menopausal women without climacteric syndrome 
В результате у женщин МПсКС мы получили достоверную сильную положительную связь $(0,886$ при $\mathrm{p}=0,05)$ между уровнями немотивированной тревожности (по методике В.В. Бойко) и психосоциального стресса (методика «Ваше самочувствие» (О.С. Копина, Л. Ридер)). Также показатель немотивированной тревожности имеет средние корреляционные связи с уровнем тревожности (шкала ИТО) $(0,655$ при $p=0,05)$ и умеренные - с «агрессивностью» (шкала ИТО) (0,433 при $p=0,05)$. Проявление немотивируемой тревожности на фоне психосоциального стресса и агрессивности указывает на взаимное увеличение этих показателей, вызванных психологическим состоянием, в котором находятся женщины с KC.

В свою очередь «тревожность», которая проявлялась как акцентуированное свойство (5,08 баллов по ИТО), имеет такие же значимые корреляционные связи, как показатель «немотивируемая тревожность» по методике В.В. Бойко, а именно - среднюю с психосоциальным стрессом (0,523 при $p=0,05)$ и умеренную с агрессивностью $(0,301$ при $p=0,05)$, что также подтверждает наличие тревожности у женщин с КС.

У показателя «сензитивность», акцентуированного в методике ИТО $(5,13)$, можно наблюдать среднюю взаимосвязь с «реактивной тревожностью» (по методике диагностики самооценки уровня тревожности; 0,546 при $\mathrm{p}=0,05)$. Умеренную - между такими показателями, как «психосоциальный стресс» $(0,271$ при $p=0,05)$ и «ригидность» $(0,310$ при $p=0,05)$. И отрицательную - с показателями шкалы «спонтанность» (по ИТО). Проявления чувствительности и впечатлительности у таких женщин напрямую зависят от переживаемого психоэмоционального стресса и непреходящей тревоги из-за сложившихся ситуаций. Это, в свою очередь, приводит к неспособности адекватного реагирования на происходящие события, следованию уже имеющихся установок и отсутствию инициативности в своем поведении.

Что касается женщин МПбКС, то преобладание показателя «интроверсия» (5,28; методика ИТО) отличает их от женщин МПсКС, т. к. «сензитивность» преобладает в обеих группах (5,49 и 5,13 соответственно; методика ИТО). По результатам корреляционного анализа у показателя «интроверсия» есть умеренная связь с показателем нервно-психического напряжения (Т.А. Немчин) $(0,301$ при $\mathrm{p}=0,05)$. Это можно интерпретировать как психологическую возможность этих женщин замыкаться в себе и ограничивать свои социальные контакты при возникновении нервно-психического давления. Общий показатель «сензитивность» имеет достоверную связь с «тревожностью» $(0,357$ при р =0,05) (ИТО) и «активностью» $(0,351$ при $p=0,05)(\mathrm{CAH})$, что существенно отличается от показателей женщин с КС. 


\section{Обсуждение результатов}

Использование комплекса взаимодополняющих диагностических методик, репрезентативность выборки и результаты статистической обработки позволили обнаружить ранее недостаточно изученные особенности личностных свойств менопаузальных женщин с наличием и отсутствием признаков климактерического синдрома.

Несмотря на определенную схожесть некоторых акцентуированных черт, для женщин с климактерическим синдромом характерно доминирование личностной тревожности, сочетающейся с высоким уровнем нервно-психического напряжения, сензитивностью и результатами самооценки. Их можно рассматривать как значимый психологический симптомокомплекс климактерического синдрома.

У женщин без признаков климактерического синдрома в качестве акцентуированных личностных особенностей представлена интроверсия в сочетании с ригидностью и отсутствием инициативности. Эти качества можно рассматривать как защитную форму поведения, минимизирующую влияние стрессорных факторов.

Полученные результаты способны дополнить представления о психологии женского климактерия. Они могут быть полезны в совершенствовании способов прогнозирования диагностики и психокоррекции климактерического синдрома, а также стать основой для продолжения исследования в плане обнаружения биоэлектрических, в частности биоэнергетических процессов, лежащих в основе обнаруженных при климактерическом синдроме личностных особенностей.

\section{Литература}

1. Агаджанян Н. А. Нормальная физиология. Учебник. - М. : МИА, 2009. - 520 с.

2. Барбараш Н. А., Чичиленко М. В., Тарасенко Н. П., Барбараш Л. С. Экстрагенитальные особенности биологии и физиологии женского организма (обзор) // Сибирский научный медицинский журнал (Бюллетень СО РАMH). - 2003. - № 3. - С. 53-58.

3. Заводнов О. П. Влияние частичной световой депривации на вегетативный, сомнологический, эндокринный и психоэмоциональный статус женщин климактерического возраста : дисс. ... канд. мед. наук. - Ростов н/Д, 2013. - 150 с.

4. Манухин И. Б., Тактаров В. Г., Шмелева С. В. Здоровье женщины в климактерии : руководство. - М. : Литтерра, 2010. - 256 с.

5. Барденштейн Л. М., Торчинов А. М. и др. Клиническая типология депрессивных расстройств у женщин в перименопаузальном периоде // Аллергология и иммунология. - 2005. - Т. 6, № 2. - С. 269-272. 
6. Moron F. J., Ruiz A., Galan J. J. Genetic and genomic insights into age at natural menopause // Genome Medicine. - 2009. - Vol. 1, Issue 76. - P. 76-78. - DOI: $10.1186 / \mathrm{gm} 76$

7. Soares C. N., Arsenio H., Joffe $H_{\text {., }}$ et al. Escitalopram versus ethinyl estradiol and norethindrone acetate for symptomatic peri- and postmenopausal women: impact on depression, vasomotor symptoms, sleep, and quality of life // Menopause. - 2006. - Vol. 13. - P.780-786.

8. Bromberger J. T., Harlow S., Avis N., et al. Racial/ethnic differences in the prevalence of depressive symptoms among middle-aged women: The Study of Women's Health Across the Nation (SWAN) // American Journal of Public Health. - 2004. - Vol. 94, Issue 8. - P. 1378-1385. - DOI: 10.2105/ AJPH.94.8.1378

9. Haines C. J., Yim S. F., Chung T. K., et al. A prospective, randomized, placebocontrolled study of the dose effect of oral oestradiol on menopausal symptoms, psychological well being, and quality of life in postmenopausal Chinese women // Maturitas. - 2003. - Vol. 44, Issue 3. - P. 207-216.

10. Prior J. C., Hitchcock C. L. The endocrinology of perimenopause: need for a paradigm shift // Frontiers in Bioscience. - 2011. - № 3. - P. 474-486.

11. Yang Y. S., Hur M. H. et al. Correlation between sonographic and endocrine markers of ovarian aging as predictors for late menopausal transition // Menopause. - 2011. - Vol. 18, Issue 2. - P. 138-145.

12. Антонова А. А., Бачило Е. В., БарыльникЮ. Б. Современный взгляд на проблему развития психических расстройств уженщин в перименопаузе // Саратовский научно-медицинский журнал. - 2012. - № 2. - С. 379-383.

13. Ельчанинов Д. В. Климактерический синдром в ранней постменопаузе: системные метаболические изменения и их негормональная коррекция : дисс. ... канд. мед. наук. - Омск, 2012. - 138 с.

14. Hickey M., Schoenaker D. A., Joffe H., et al. Depressive symptoms across the menopause transition:findings froma large population-based cohort study // Menopause. - 2016. - Vol. 23, Issue 12. - P. 1287-1293. - DOI: 10.1097/ GME.0000000000000712

15. Maki P. M., Freeman E. W., Greendale G. A., et al. Summary of the National Institute on Aging-sponsored conference on depressive symptoms and cognitive complaints in the menopausal transition // Menopause. - 2010. Vol. 17, Issue 4. - P. 815-822. - DOI: 10.1097/gme.0b013e3181d763d2

16. Дзугаева И. О., Абдуллаева С. С., Шипиевский Б. М. Профилактика и лечение климактерического синдрома в постменопаузе // Вестник РУДН. Сер. «Медицина». - 2008. - № 5. - С. 220-227.

17. Дюкова Г.М., Сметник В. П., Назаров Н. А. Состояние психовегетативной и сексуальнойсферуженщинвперименопаузе. Руководство по климак- 
су : Руководство для врачей / под ред. В. И. Кулакова, В. П. Сметник. - М. : МИА, 2001. - 592 с.

18. Танкиева 3. М. Влияние антигипертензивной терапии на течение климактерического синдрома : дисс. ... канд. мед. наук. - М., 2010. - 128 с.

19. Mirza F. S., Ong P., Collins P. et al. Effects of estradiol and the angiotensin II receptor blocker irbesartan on vascular function in postmenopausal women // Menopause. - 2008. - Vol. 15. - P. 44-50.

20. Дмитриева Т. Б., Качаева М. А. Лечение реактивных депрессий у женщин в период климакса // Российский психиатрический журнал. Приложение «Депрессия у женщин». - 2001. - № 4. - С. 7-11.

21. Психиатрия. Национальное руководство. Краткое издание / под ред. Т. Д. Дмитриевой, В. Н. Краснова, Н. Г. Незнанова. - М. : ГЭОТАР-Медиа, 2015. - 622 c.

22. Bromberger J. T., Schott L., Kravitz H. M., et al. Risk factors for major depression during midlife among a community sample of women with and without prior major depression: are they the same or different? // Psychological Medicine. 2015. - Vol. 45, Issue 8. - P. 1653-1664. - DOI: 10.1017/s0033291714002773

23. Дороженок И. Ю. Тревожные и болевые расстройства в общемедицинской практике (аспекты коморбидности и терапии) // Медицинский совет. - 2012. - № 4. - С. 98-104.

24. Джебашвили М. М. Значение личностных особенностей при климактерическом синдроме // Российский медицинский журнал. - 2001. № 3. - С. 159-163.

25. Пахомов А. А. Прогнозирование и коррекция патологии психогенного регистра у женщин среднего и пожилого возраста : дисс. ... канд. мед. наук. - СПб., 2011. - 139 с.

26. Тювина Н. А. Дифференциальная диагностика и лечение депрессивных расстройств у женщин в период климактерия // Неврология, нейропсихиатрия, психосоматика. - 2011. - № 1.-С. 66-71.

27. Moustafa Ahmed A., Tindle R., Frydecka D., MisiakB. Impulsivity and its relationship with anxiety, depression and stress // Comprehensive Psychiatry. Vol. 74. - P. 173-179. - DOI: 10.1016/j.comppsych.2017.01.013

28. Freeman E. W., Sammel M. D., Lin H., et al. Associations of hormones and menopausal status with depressed mood in women with no history of depression // Archives of General Psychiatry - 2006. - Vol. 63, Issue 4. P. 375-382. - DOI: 10.1001/archpsyc.63.4.375

29. Srivastava D. P., Woolfrey K. M., Evans P. D. Mechanisms underlying the interactions between rapid estrogenic and BDNF control of synaptic connectivity // Neuroscience. - 2013. - Vol. 3, Issue 239. - P.17-33. - DOI: 10.1016/J. NEUROSCIENCE.2012.12.004 
30. Диагностика здоровья. Психологический практикум / под ред. Г. С. Никифорова. - СПб. : Речь, 2013. - 950 с.

\section{References}

1. Agadzhanyan N. A. Normal'naya fiziologiya [Normal physiology]. Moscow, MIA Publ., 2009. 520 p.

2. Barbarash N. A., Chichilenko M. V., Tarasenko N. P., Barbarash L. S. Extragenital features of the biology and physiology of the female organism: an overview. Sibirskii nauchnyi meditsinskii zhurnal (Byulleten' SO RAMN) - The Siberian Scientific Medical Journal (The Bulletin of Siberian Branch of Russian Academy of Medical Sciences), 2003, no. 3, pp. 53-58 (in Russian).

3. Zavodnov O. P. Vliyanie chastichnoi svetovoi deprivatsii na vegetativnyi, somnologicheskii, endokrinnyi i psikhoemotsional'nyi status zhenshchin klimaktericheskogo vozrasta [Impact of partial light deprivation on the vegetative, somnological, endocrine, and psychoemotional status of climacteric women]. Diss. Cand. Sci. (Med.). Rostov-on-Don, 2013. 150 p.

4. Manukhin I. B., Taktarov V. G., Shmeleva S. V.Zdorov'e zhenshchiny v klimakterii [Women's health in menopause]. Moscow, Litterra Publ., 2010. 256 p.

5. Bardenshtein L. M., Torchinov A. M. Clinical typology of depressive disorders in perimenopausal women. Allergologiya i immunologiya-Allergology and Immunology, 2005, V. 6, no. 2, pp. 269-272 (in Russian).

6. Moron F. J., Ruiz A., Galan J. J. Genetic and genomic insights into age at natural menopause. Genome Medicine, 2009, V. 1, Issue 76, pp. 76-78. DOI: 10.1186/gm76

7. Soares C. N., Arsenio H., Joffe H., et al. Escitalopram versus ethinyl estradiol and norethindrone acetate for symptomatic peri- and postmenopausal women: impact on depression, vasomotor symptoms, sleep, and quality of life. Menopause, 2006, V. 13, pp. 780-786.

8. Bromberger J. T., Harlow S., Avis N., et al. Racial/ethnic differences in the prevalence of depressive symptoms among middle-aged women:The Study of Women's Health Across the Nation (SWAN). American Journal of Public Health, 2004, V. 94, Issue 8, pp. 1378-1385. DOI: 10.2105/AJPH.94.8.1378

9. Haines C. J., Yim S. F., Chung T. K., et al. A prospective, randomized, placebo-controlled study of the dose effect of oral oestradiol on menopausal symptoms, psychological well being, and quality of life in postmenopausal Chinese women. Maturitas, 2003, V. 44, Issue 3, pp. 207-216.

10. Prior J. C., Hitchcock C. L. The endocrinology of perimenopause: need for a paradigm shift. Frontiers in Bioscience, 2011, no. 3, pp. 474-486.

11. Yang Y. S., Hur M. H. et al. Correlation between sonographic and endocrine markers of ovarian aging as predictors for late menopausal transition. Menopause, 2011, V. 18, Issue 2, pp. 138-145. 
12. Antonova A. A., Bachilo E. V., Baryl'nik Yu. B. A modern view on mental disorders in perimenopausal women. Saratovskiy Nauchno-meditsinskiy Zhurnal-Saratov Journal of Medical Scientific Research, 2012, no. 2, pp. 379-383 (in Russian).

13. El'chaninov D. V. Klimaktericheskii sindrom v rannei postmenopauze: sistemnye metabolicheskie izmeneniya i ikh negormonal'naya korrektsiya [Climacteric syndrome in early postmenopause: System metabolic changes and their non-hormonal correction]. Diss. Cand. Sci. (Med.). Omsk, 2012. 138 p.

14. Hickey M., Schoenaker D. A., Joffe H., et al. Depressive symptoms across the menopause transition: findings from a large population-based cohort study. Menopause, 2016, V. 23, Issue 12, pp. 1287-1293. DOI: 10.1097/ GME.0000000000000712

15. Maki P. M., Freeman E. W., Greendale G. A., et al. Summary of the National Institute on Aging-sponsored conference on depressive symptoms and cognitive complaints in the menopausal transition. Menopause, 2010, V. 17, Issue 4, pp. 815-822. DOI: 10.1097/gme.0b013e3181d763d2

16. Dzugaeva I. O., Abdullaeva S. S., Shipievskii B. M. The prophylaxis and treatment of climacteric syndrome in postmenopause. Vestnik Rossiiskogo universiteta druzhby narodov. Seriya: Meditsina - RUDN Journal of Medicine, 2008, no. 5, pp. 220-227 (in Russian).

17. Dyukova G. M., Smetnik V. P., Nazarov N. A. Psychovegetative and sexual spheres in perimenopausal women. In: V. I. Kulakov, V. P. Smetnik (eds.) Rukovodstvo po klimaksu: Rukovodstvo dlya vrachei [Menopause: A guide for physicians]. Moscow, MIA Publ., 2001. 592 p.

18. Tankieva Z. M. Vliyanie antigipertenzivnoi terapii na techenie klimaktericheskogo sindroma [Impact of antihypertensive therapy on climacteric syndrome]. Diss. Cand. Sci. (Med.). Moscow, 2010. 128 p.

19. Mirza F. S., Ong P., Collins P. et al. Effects of estradiol and the angiotensin II receptor blocker irbesartan on vascular function in postmenopausal women. Menopause, 2008, V. 15, pp. 44-50.

20. Dmitrieva T. B., Kachaeva M. A. Treatment for reactive depression in menopausal women. Rossiiskii psikhiatricheskii zhurnal. Prilozhenie "Depressiya u zhenshchin" - Russian Journal of Psychiatry. "Depression in Women" Supplement, 2001, no. 4, pp. 7-11 (in Russian).

21. Dmitrieva T. D., Krasnov V. N., Neznanov N. G. Psikhiatriya. Natsional'noe rukovodstvo. Kratkoe izdanie [Psychiatry: National guide]. Moscow, GEOTARMedia Publ., 2015. 622 p.

22. Bromberger J. T., Schott L., Kravitz H. M., et al. Risk factors for major depression during midlife among a community sample of women with and without prior major depression: are they the same or different? Psychological Medicine, 2015, V. 45, Issue 8, pp. 1653-1664. DOI: $10.1017 /$ s0033291714002773 
23. Dorozhenok I. Yu. Anxiety and pain disorders in medical practice (comorbidity and therapy aspects). Meditsinskiy Sovet - Medical Council, 2012, no. 4, pp. 98-104 (in Russian).

24. Dzhebashvili M. M. Personality characteristics in climacteric syndrome. Rossiiskii meditsinskii zhurnal - Medical Journal of the Russian Federation, 2001, no. 3, pp. 159-163 (in Russian).

25. Pakhomov A. A. Prognozirovanie i korrektsiya patologii psikhogennogo registra $u$ zhenshchin srednego i pozhilogo vozrasta [Prediction and correction of psychogenic register pathology in middle-aged and elderly women]. Diss. Cand. Sci. (Med.). St. Petersburg, 2011. 139 p.

26. Tyuvina N. A. Differential diagnosis and treatment of depressive disorders in menopausal women. Nevrologiya, Neiropsikhiatriya, Psikhosomatika-Neurology, Neuropsychiatry, Psychosomatics, 2011, no. 1, pp. 66-71 (in Russian).

27. Moustafa Ahmed A., Tindle R., Frydecka D., Misiak B. Impulsivity and its relationship with anxiety, depression and stress. Comprehensive Psychiatry, V. 74, pp. 173-179. DOI: 10.1016/j.comppsych.2017.01.013

28. Freeman E. W., Sammel M. D., Lin H., et al. Associations of hormones and menopausal status with depressed mood in women with no history of depression. Archives of General Psychiatry, 2006, V. 63, Issue 4, pp. 375-382. DOI: 10.1001/archpsyc.63.4.375

29. Srivastava D. P., Woolfrey K. M., Evans P. D. Mechanisms underlying the interactions between rapid estrogenic and BDNF control of synaptic connectivity. Neuroscience, 2013, V. 3, Issue 239, pp. 17-33. DOI: 10.1016/J. NEUROSCIENCE.2012.12.004

30. Nikiforov G. S. (ed.) Diagnostika zdorov'ya. Psikhologicheskii praktikum [Health diagnostics: Psychological practical guide]. St. Petersburg, Rech' Publ., 2013. 950 p. 